\title{
1. Mobility across the life course: an introduction to a dialogue
}

\author{
Henrike Rau and Joachim Scheiner
}

\subsection{INTRODUCTION}

Mobility has become a cornerstone of modern life today, with participation in economic, social and cultural events and activities being largely inconceivable without some form of travel. Both the extension of daily activity spaces and inter-regional residential relocation have contributed to economic growth, the spatial division of labour, specialisation, cultural and social integration and, perhaps most importantly in the context of this book, changes in people's life courses. At the same time, the downsides of increasing and accelerating mobility for society and the environment are increasingly evident, not least in the context of current climate change debates that identify the transport sector as a major greenhouse gas emitter and, more generally, contributor to unsustainable ways of life.

The expansion of activity spaces and significant shifts in mobility culture over the past century are inextricably linked to dramatic changes in transport systems and infrastructure, including the growing dominance of the private car, increases in air travel, the development of high-speed trains and, most recently, the emergence of ICT-enabled sharing systems, new propulsion technologies, the virtualisation of many daily activities and autonomous vehicles. At the same time, these developments have presented unprecedented challenges for transport policy, in particular given that transport growth has come at high environmental, social and (external) economic costs. For example, links between public health, social exclusion and car dependency are only now being recognised as major sustainability challenges, with significant implications for both social and transport policies (Hodgson et al., 2012; Jones and Lucas, 2012; Milne, 2012; Mattioli et al., 2019).

As mentioned previously, changes in mobility have also contributed to dramatic changes in life courses. This refers to the life stages to be passed through, their sequence and ordering, and the kinds of socio-cultural meanings people and societies bestow upon them. For example, in many societies 
young people's transition to adulthood was traditionally accompanied by them leaving the parental home (at least for some time), marrying and having children, all within a short period of time in their early 20s. Today, the transition to adulthood is no longer necessarily tied to leaving home, marriage, or starting a family. Instead, people may remain single, decide to cohabit instead of getting married, or live in a succession of temporary partnerships. Of course, this may not be by choice but reflect structural conditions. For example, a combination of rapidly rising house prices and rents in many urban centres in Europe and temporary or long-term increases in youth unemployment (e.g. in the aftermath of the financial and economic crisis in 2007/8) has meant that many young people are no longer in a position to move out of their parents' home (e.g. Mínguez, 2016). The implications of these life course-related changes for mobility practices and transport systems are wide-ranging and manifold. For example, drops or delays in young people acquiring a driving licence occur in many urban parts of Europe, partly because of economic hardship but also due to improved public transport infrastructure, the revival of cycling and ICT use in lieu of actual travel (e.g. Chatterjee et al., 2018; Delbosc et al., 2019).

Inquiries into people's mobility practices across the life course have emerged as a novel approach to mobility research and transport studies (Lanzendorf, 2003; Scheiner, 2007; Chatterjee et al., 2013; Oakil, 2013; Goulias and Pendyala, 2014; Sharmeen et al., 2014; Rau and Manton, 2016; Rasouli and Timmermans, 2017). These studies look at how aspects of daily mobility (including travel behaviour, vehicle ownership/availability, or season ticket ownership) evolve over time. The focus is firmly on the individual level and mid- to long-term trends. Moreover, efforts are made to better understand and explain stability and change across the life course regarding mobility practices. On a practical level, research in this area aims to identify particular 'turning points' in the life course that serve as opportunities for deliberately shifting mobility practices towards greater sustainability. Here, a strong emphasis on discrete life events and what Rau and Manton call 'mobility milestones', that is, life events explicitly related to mobility such as the acquisition of a driving licence and public transport pass, contrasts with a scarcity of work on more gradual changes in mobility practices across the life course. Concerning the relevance of these mobility-biographical studies for policy development, efforts have been made to capture the effects (or lack thereof) of voluntary travel behaviour change campaigns and travel demand management on mode choice (Roby, 2010; Enoch, 2012), including in the context of major life events such as residential relocation (Schäfer et al., 2012). Studies that investigate the impact of disruptive events or deliberate changes in transport provision or urban structure on the mobility practices of people constitute another important strand of research (Marsden and Docherty, 2013). 
Life course and biography research have a rich tradition in various disciplines (see Mortimer and Shanahan, 2003, for life course studies; Chamberlayne et al., 2000; Roberts, 2002, for biography studies). Time geography provides an important point of origin for mobility biographies, as Hägerstrand's (1970) idea of space-time paths has early - though only rarely - been applied to the life span (Martensson, 1979). Time geography also inspired early seminal work that categorised travel behaviour by life cycle stages (Hanson and Hanson, 1981; Kostyniuk and Kitamura, 1982; Salomon and Ben-Akiva, 1983), with clear references to life course dynamics (Clarke et al., 1982). The life cycle perspective was applied in dynamic transport models such as MIDAS (Goulias and Kitamura, 1997) or ALBATROSS (Timmermans and Arentze, 2011). In hindsight, these early studies have laid the foundation for the subsequent emergence of the mobility biographies approach. The term itself was introduced by Lanzendorf (2003), with similar ideas being developed by others around the same time (e.g. Van der Waerden et al., 2003).

\subsection{SETTING THE STAGE FOR THIS BOOK}

To date, insights from mobility biographies research have largely been disseminated through journal articles and published $\mathrm{PhD}$ studies. The field has grown substantially over the past few years, and time has come to assemble an edited volume of work done by leading scholars in the field. This book is the first to do so. However, it goes beyond a mere stocktaking exercise by presenting critical reflections of previous work that aim to contribute to the conceptual and methodological advancement of the field. To achieve this goal, the collection assembles chapters based on a wide variety of conceptual and methodological approaches. While much research in the field has hitherto relied on statistical analyses of travel behaviour data, this book presents a more balanced mix of quantitative, qualitative and mixed-methods work. Contributing authors represent a variety of backgrounds, including disciplines such as geography, sociology, psychology, transport planning and civil engineering. Moreover, the book prioritises detailed theoretical and methodological reflections, thus departing from much previous mobility biographies research that has been predominantly empirical and limited in its theoretical and conceptual outlook.

This emphasis on critical theoretical and methodological reflection aims to stimulate debate on the interdisciplinary and cross-methodological character of the field. It also responds to growing criticism of the mobility biographies approach in its current form because of its conceptual and practical limitations (see Sattlegger and Rau, 2016; Plyushteva and Schwanen, 2018; Scheiner, 2018). These include the theoretical weakness of the approach, in addition to a lack of integration of the diverse strands of literature that have helped to make sense of certain aspects of stability and change in mobility over the life course. 
Questions have also been raised regarding the field's preoccupation with the household level, given the social reach of mobility practices far beyond the household, as well as its lack of attention to interdependencies between partners or parents and children within a household. Concerning methodological weaknesses, scholars have drawn attention to reliability issues associated with retrospective data collection, the more or less exclusive preoccupation of many studies with mode choice, as opposed to different mobility dimensions and their interlinkages, and an overemphasis on the time period before, during and after particular critical life events, as opposed to much longer sequences over the life span.

Perhaps the most important criticism refers to the dominance of quantitative approaches in the field that are capable of answering 'what' questions such as the prevalence of certain mobility-related reactions to key life events. In fact, some have described mobility biographies studies as unnecessarily narrow in their focus on statistical associations between variables pre-defined by researchers. This has led to calls for alternative approaches that adopt a qualitative-hermeneutic understanding of people's narratives about their own biographies. For example, Sattlegger and Rau (2016) suggest a reconstructive-interpretative approach that views people's memories as oral history that shapes present action. This qualitative approach shifts attention towards latent, less conscious structures of meaning that underpin observable mobility practices, treating biographies as outcomes of social relations and interactions that do not necessarily follow linear temporal structures and cause-impact relationships and that fuse social conditions with subjective experiences (Sattlegger and Rau, 2016). This also implies that debates concerning the quality of retrospective data need to move away from the current narrow preoccupation with reliability and validity measures and towards broader discussions concerning the meaning of selective (and thus potentially 'unreliable') memories regarding mobility practices across the life course.

Limitations nevertheless remain concerning the use of biographical narratives in mobility research, including the quality of information gained. Here, mixed-methods approaches that combine narrative interview data with other sources of historical or life course information could offer new and promising avenues for rigorous research. Examples of the use of methodological triangulation and relational data analysis in other fields of biographical and life course research such as family studies (Finch and Mason, 1993; Perlesz and Lindsay, 2003; Vogl et al., 2019), including those that explicitly deal with dissonant data (Perlesz and Lindsay, 2003; Vogl et al., 2019), offer direction and guidance regarding data quality assurance in biographical research (cf. Worth and Hardill, 2015, for a collection of papers that reflect critically on methodological aspects of social-scientific life course research more generally, and data quality issues in biographical research in particular). 
Epistemological positions occupied by mobility biographies researchers range from 'positivist-structuralist' perspectives to hermeneutic-interpretivereconstructive views. Some attempts have been made in transport studies to reduce the gap between these positions (e.g. Scheiner, 2005; Goetz et al., 2009; Hanson, 2010; Schwanen, 2011). This said, persistent tensions and frictions between these positions may actually benefit the field, serving as potent catalysts for conceptual and methodological advancement. A key aim of the book is thus to initiate a continuous and fruitful dialogue between advocates of divergent or even conflicting epistemological positions and methodological approaches in the field. At the same time, it aims to provide researchers, students and practitioners with an overview of the current state of the field, with a view to opening up new and innovative avenues for future mobility biographies research. As editors of this book, we are most grateful to the authors of the chapters for sharing their work and contributing to this dialogue.

In what follows, we provide a succinct, but comprehensive, overview of the basic tenets of the mobility biographies approach. To gain a deeper understanding of the characteristics of the field, we refer readers to a number of well accessible journal and conference papers (Chatterjee and Scheiner, 2015; Müggenburg et al., 2015; Sattlegger and Rau, 2016; Scheiner, 2018).

\subsection{MOBILITY BIOGRAPHIES: CONCEPTUAL FOUNDATIONS}

There are a number of key concepts in life course studies that have also been utilised in mobility biographies studies. The central idea is that lives can be understood as temporal paths or trajectories, and that any point on such a path is a result of past experiences and decisions made, as well as future expectations, anticipations and aspirations (Giele and Elder, 1998). These trajectories can be divided into distinct life stages (or phases) that coincide with particular sets of social roles, responsibilities and statuses (e.g. employed father, student mother). Observable changes in social role or status are called life course transitions, and may coincide with particular life events (e.g. entry into school, marriage) (Sharmeen et al., 2014; Chatterjee and Scheiner, 2015; Müggenburg et al., 2015).

Concerning interactions between decisions, a hierarchy of long-, mediumand short-term decisions that considers past long-term decisions to set the preconditions for future short- and long-term decisions has been in frequent use (Salomon and Ben-Akiva, 1983; Lanzendorf, 2003; Miller, 2005; Oakil et al., 2011; Goulias and Pendyala, 2014). For instance, decisions regarding residential location (long-term, one-off) are typically assumed to influence vehicle ownership (medium-term), which in turn shapes daily mobility practices (short-term). 
The mobility biographies approach features five major conceptual elements.

1. Life courses are treated as intersecting individual trajectories that shape and reflect wider societal conditions. Hence, mobility biographies need to be understood as the product of historical circumstances and processes in time and space that affect different cohorts and social groups differently. For example, there is ample evidence of gender differences regarding the significance of particular life events for mobility decisions.

2. The habitual or routine character of much daily travel results in considerable stability over time. This said, resistance to change may also be a personality trait that is particularly pronounced in some people and that either complements or contradicts societal norms and prescriptions regarding people's openness or resistance to change.

3. Close links exist between individual mobility biographies and other domains of the life course. These domains typically include education/ employment, housing, and the family/household and tend to be interrelated (as exemplified by the close connection between mobility and residential location). In contrast, other domains such as health or social networks beyond the household have been less well studied.

4. A large proportion of empirical work on mobility biographies has focused on the impact of clearly defined life events and more or less sudden transitions on mobility practices. These events can be classified into: (1) life events that directly relate to the private sphere or the realm of work (e.g. De Vos et al., 2018; Bruns and Matthes, 2019, on residential relocation; Rau et al., 2019, for work on firm relocation and staff mobility patterns), including critical incidents at the individual or household level, such as accidents; (2) explicitly mobility-related events such as licence acquisition (i.e. mobility milestones, as defined by Rau and Manton, 2016); and (3) exogenous events that are not per se related to the life course but may have a lasting impact on people's mobility practices and those of entire communities or regions, including disruptive events at the level of transport provision, and deliberate efforts to change travel behaviour. Events may also be classified as deliberate (e.g. decision to get married), foreseeable but unavoidable events (such as reaching retirement age), or events entirely beyond the control of a person or household (such as road closure, or an accident) (Oakil et al., 2011, p. 221). For instance, a disruptive event in the transport infrastructure may be exogeneously imposed ('exogenous' here from the perspective of the responsible authority) or planned, and in the latter case it may or may not be a deliberate intervention to achieve travel behaviour change. Of course, decisions regarding the level of deliberation and voluntariness of a particular activity tend to be both subjective and informed by dominant political ideologies. For example, some commentators and 
academics have linked the more or less uncritical endorsement of choice as an inherently 'good thing' to the spread of neoliberal thinking in many countries since the 1980s (see also Schwartz's 2004 book The Paradox of Choice in which he critiques this uncritical embracing of 'pro-choice perspectives' as inherently positive, showing instead the many negative aspects of too much choice).

Given the dominance of inquiries into distinct life events and sudden ruptures or shifts and their impact on mobility, more gradual change processes have received much less attention in mobility biographical research to date. This knowledge gap is partly related to a lack of conceptual work on what constitutes a life event, including how non-conspicuous events can fundamentally reshape mobility practices (e.g. a book or documentary that transforms a person's perspective of what it means to be mobile, and how mobility impacts on society and the environment). Similarly, variations in the quality and duration of life events both within and between countries and their mobility-related effects remain seriously under-researched.

5. An individual's life course cannot be seen as separate from the life courses of others in their social environment. Instead, highly complex sets of socialisation processes both reflect and promote the emergence of 'linked lives' (Elder et al., 2006). Given the general orientation of the mobility biographies approach towards conceptual and methodological individualism, this linking of lives, including through processes of mobility (socialisation) has received relatively little attention (but see Rau and Sattlegger, 2018, for an example of an in-depth qualitative inquiry into shared journeys and linked lives). This budding area of inquiry highlights the central role of personal social networks for travel involving household or family members (Ho and Mulley, 2015) as well as interactions with people beyond the household (Lin and Wang, 2014; Sharmeen et al., 2014).

The character of much mobility biographies work today closely mirrors key features of life course research more generally. Here, the life course is typically conceived as a sequence of events and role transitions that a person lives through from birth to death (Elder et al., 2006). In contrast, biographical research in the social sciences tends to view people's biography as the result of their self-reflective, meaningful action within the temporal structure of their own life (Sackmann, 2007, p. 50). Accordingly, biography studies tend to reconstruct the subjective meanings someone associates with their own life (Antikainen and Komonen, 2003) while life course studies attempt to measure and potentially quantify sequences and structures in people's lives, e.g. by asking for pre-defined stations, events or sequences. This said, some efforts have been made to merge the benefits of these two approaches (see, for example, Holstein and Gubrium's (2000) constructivist work on the life 
course). In sum, the term 'mobility biography' has been utilised across a wide range of (pseudo-)longitudinal studies, many of which deploy quantitative modes of inquiry, and many authors in this book use it. Importantly, we believe that the term remains sufficiently open to facilitate fruitful dialogues between advocates of different conceptual and methodological approaches to researching travel and mobility practices across the life course.

\subsection{STRUCTURE AND CONTENT OF THIS BOOK}

This book features two distinct yet interrelated parts. Following this introductory chapter, Part I includes six chapters (Chatterjee and Clark; Rau, Popp and Mahne-Bieder; Kroesen; Crastes dit Sourd and Calastri; Mattioli; Ohnmacht, $\mathrm{Vu}$ and von Arx) that focus on theoretical, conceptual and methodological developments. An explicit focus on methodological challenges and opportunities inherent in qualitative, quantitative and mixed-methods approaches is also evident in Part II, which brings together a set of original empirical studies that cover different life stages and diverse transport modes (cars, bicycles, public transport, e-bikes) (Klein and Smart; Scheiner and Holz-Rau; Priya Uteng and Farstad; Driller, Thigpen and Handy; Van Acker, Mulley and Ho; Goulias, McBride and Su; Marincek, Ravalet and Rérat). Concerning the geographical range of work presented, this edited collection includes studies from the USA and Australia, thereby placing some emphasis on more car-dependent societies outside of Europe. This said, the mobility biographies approach originates from Central Europe, a fact that is reflected in five of the contributions to this book. Rau and Scheiner provide a final chapter in which they take a reflective look back to subsequently look ahead to possible future advancements in the field of mobility biographies studies.

Chatterjee and Clark (Chapter 2) take examples from their own qualitative and quantitative research on car ownership changes and car sharing to establish an explicit dialogue between the two methodological approaches. They deviate from the common idea of 'qualitative research being used to formulate theory and quantitative research being used to test theory', arguing rather that the two types of research form an iterative research process that can generate new knowledge in a largely unpredictable way. They find that the two types of research can complement each other, partly because they address different research questions. For example, in this chapter quantitative panel data are shown to be highly suitable to investigate prevalences and magnitudes of associations. In contrast, qualitative biographical interviews demonstrably reveal interviewees' subjective perspectives. Moreover, they allow interviewees to reflect on whether a change is likely to be a turning point initiating longer-lasting changes, as opposed to a moment of temporary diversion from established mobility routines and habits. 
Rau, Popp and Mahne-Bieder (Chapter 3) draw on the research design and methodological tools of their recent study of non-cyclists in Germany to critically examine the merits and pitfalls of mixed-methods approaches to mobility biographies research. Their critical reflections lead them to advocate for a technical approach to mixing methods that can accommodate much of the existing diversity of ontological and epistemological viewpoints within the mobility biographies research community. Importantly, their work demonstrates how an open and flexible handling of different modes of inquiry and related methodological tools can enhance the methodological strengths and capacities of this important field of social-scientific and interdisciplinary mobility research. In particular, their chapter aptly demonstrates the potential of in-depth qualitative work for enhancing the explanatory power and interpretative rigour of analytical processes that fuse different types of data. At the same time, Rau et al. caution against the uncritical, superficial and unreflective deployment of mixed-methods designs, which could undermine budding efforts to fuse quality and quantity in mobility biographies research and foster a constructive dialogue between advocates of different methodological traditions.

Kroesen (Chapter 4) starts off his chapter with the controversial claim that mobility biography research has reached its limits, especially regarding its ability to test existing or newly-developed theoretical propositions. He subsequently puts forward an alternative model of travel behaviour change that rests upon the use of latent transition modelling to test various theoretical assumptions, including the concept of habit, forms of cognitive dissonance and social influence. Earlier empirical work by the author serves to demonstrate the usefulness of latent transition modelling. These studies show that the strength of habits and cognitive consonance between attitudes and behaviour are both connected with less behavioural change. Interestingly, whenever members of a 'cognitively dissonant' group switched to another (consonant) group, they were more likely to change their attitudes than their behaviour. With respect to social influence, Kroesen's empirical examples suggest that social norms at the household level play a key important role in shaping shifts in travel behaviour. From his discussion, Kroesen suggests avenues for future research, including how latent transition modelling can be connected to qualitative research.

Crastes dit Sourd and Calastri (Chapter 5) offer highly relevant methodological reflections on the nature of mobility biography data. They do so by drawing on a comprehensive, multi-dimensional survey that combines information about respondents' travel habits, energy use and residential choices with sociodemographics, social networks and data collected using a life course calendar and a two-week activity-travel diary. Such an effort inevitably places a large burden on respondents, which in turn raises interesting questions about the quality of data collected and the level of personal commitment needed to complete the survey in a satisfactory way. To cast some light on these issues, 
Crastes dit Sourd and Calastri model various outcome variables that serve as proxies for two latent variables: (1) a hectic lifestyle with high levels of activity, and (2) survey engagement. They find that the complexity of their survey implies that respondent engagement significantly influences data quality. They then draw the conclusion that specific analytical tools can help isolate the effects of engagement from the actual lifestyle of a respondent as long as there are variables that are affected by either engagement or actual lifestyle, but not by both. The inclusion of survey items that measure survey engagement more directly could also present a possible way forward.

Focusing on long-distance travel, Mattioli (Chapter 6) presents convincing arguments that daily travel and long-distance travel raise very different policy problems, some of which can be fruitfully addressed through a life-course perspective. He reviews three strands of mobility biographies work with respect to their theoretical frameworks. Lotta Frändberg's (2008) work on international mobility biographies of young Swedes receives particular attention because of its innovative view of less habitualised forms of long-distance travel. The chapter concludes by highlighting three notions that may guide empirical research on long-distance travel using a life course perspective: skills and dispositions, social networks and social practices.

Ohnmacht, Vu and von Arx (Chapter 7) present theoretical considerations on the links between the digitalisation of the labour market, the emergence of coworking spaces and the social and spatial restructurings of job-mobility biographies. Focusing on rural Switzerland, the authors show how coworking spaces support flexible and remote forms of shared working space. They argue that digitalisation supports job mobility biographies that may decrease activity spaces by weakening the attraction of urban centres. This has the potential to reduce greenhouse gas emissions from the transport sector more generally, and commuters in particular. Furthermore, their work suggests that investigating job-mobility biographies in coworking spaces can benefit from a mix of data sources and methodological tools.

Klein and Smart (Chapter 8) examine the occurrence, duration and causes of episodes of carlessness in US households using data from the Panel Study of Income Dynamics (PSID) that span half a century (1968-2017). They use survival analysis to examine the factors that influence the likelihood that householders will experience one or more periods of carlessness across their life course. They find that poor and minority households experience longer and more frequent episodes of carlessness, although differences between poor(er) and (more) affluent groups appear to be shrinking over time. Lack of income is the strongest predictor for having episodes of carlessness, in addition to other significant factors such as residential location, race/ethnicity, age, life events in the household and employment domains. The chapter makes a case for looking 'beyond the surface' of a seemingly homogeneous car society. 
Scheiner and Holz-Rau (Chapter 9) use panel data to examine changes in car access from one year to the next in Germany. They focus on couples who share a car, arguing that this is where re-allocations of car use as an effect of life events are most likely to occur. They link the mobility biographies approach with research on intra-household interdependencies, and take a gendered perspective by estimating a multi-group path model that accounts for differences between men and women, and interactions between the two partners' time use and trip patterns. They find multiple interactions between two partners in the baseline year (prior to change) as well as over time. Concerning the birth of children, the results suggest stronger effects of first births than higher-order births on time use, trip-making and car allocation.

Priya Uteng and Farstad (Chapter 10) present insights from a mixed-methods study of car sharing in Oslo. Adopting a critical view of individualist approaches to travel behaviour change, they subsequently frame their work using a practice-theoretical approach. Drawing on cross-sectional qualitative and quantitative data, they distinguish between users at different life stages (singles, couples without children, couples with children), but largely of the same age. By structuring their results along the three elements of materiality, skills and meanings, they draw a complex picture of car sharing as a set of social practices that may be taken as starting points for policy initiatives.

Driller, Thigpen and Handy (Chapter 11) report on qualitative research on cycling in Davis, CA, USA; a community known for its high cycling mode use. The authors conducted interviews with 25 parent-child (mostly mother-girl) dyads, where the children were aged 11-13. The topics analysed are cycling attitudes and behaviours and the influence of parental behaviour and attitudes on their child's cycling and attitudes towards cycling. Interestingly, parental attitudes towards cycling in general had little influence on their child's cycling. However, parental attitudes towards their own child cycling proved to be highly relevant.

Parental decisions regarding their child cycling or not rested upon a limited number of criteria, including distance, school site, activity scheduling, barrier negotiation and parental requirements to cycle. The latter meant that parents urged the child to cycle, fostering negative attitudes towards cycling among children.

Van Acker, Mulley and $\mathrm{Ho}$ (Chapter 12) use retrospective data from Australia to investigate how childhood experiences in housing and mobility shape residential and mode choices later in life. They place some emphasis on the role of subjective variables such as attitudes, and they permit the associations to vary between three generations (Babyboomers, Generation X, Generation Y) using a multi-group path analysis. They find effects of attitudes on mode choice that vary by generation, and path dependencies in that childhood experiences affect later residential perceptions and travel attitudes. This leads the authors 
to promote an understanding of mobility as a set of social practices rooted in (potientially deep-seated) experiences made in the past.

Goulias, McBride and Su (Chapter 13) present a time use analysis of data collected in Pennsylvania, USA. Departing from standard time use studies that compare average values of time use devoted to various activities and/or trips, they examine daily patterns in their entirety, paying particular attention to sequences of activities and trips. These sequences are then classified according to for whom an activity or trip is performed. Using cluster analysis, the authors identify six distinct patterns that closely relate to life cycle stage. Lower levels of complexity in daily patterns are evident for children, retirees and people with disabilities. This contrasts with highly complex activity patterns among people with children, especially those who are engaged in paid work outside the home. Working parents are also those who allocate the highest amount of travel time to the benefit of others.

Marincek, Ravalet and Rérat (Chapter 14) report from a mixed methods study about the adoption of e-bikes in Lausanne, Switzerland. Based on qualitative interviews with e-cyclists, they distinguish between resilient and restorative adopters. Resilient adopters are those who cycled more or less continuously before purchasing an e-bike. Restorative adopters purchase an e-bike to return to cycling after an interruption of several years. The authors use these two types of cycling trajectories as an outcome variable in a binary logit regression that seeks to uncover differences between the two types regarding demographics, mode ownership and intensity of cycling. As a result, resilient users - cyclists switching to e-bike - are more likely to be older, male users, with a low probability of owning cars or motorcycles, but a high probability of using car sharing and intensive e-bike use.

Finally, Rau and Scheiner (Chapter 15) present a summary of the book, with a view to capturing past and current trends in mobility biographies research in relation to theoretical and methodological developments, geographical reach and policy relevance. Their concluding chapter also offers some reflections on possible futures, especially regarding opportunities for closer conceptual and methodological integration that is capable of accommodating the views and interests of a very diverse mobility biographies research community.

\section{REFERENCES}

Antikainen, A., Komonen, K. (2003). Biography, life course, and the sociology of education. In Torres, C. A., Antikainen, A. (eds.). The international handbook on the sociology of education. Lanham, MD: Rowman and Littlefield, pp. 143-159.

Bruns, A., Matthes, G. (2019). Moving into and within cities - interactions of residential change and the travel behavior and implications for integrated land use and transport planning strategies. Travel Behaviour and Society 17, 46-61. 
Chamberlayne, P., Bornat, J., Wengraf, T. (2000). The turn to biographical methods in social science: comparative issues and examples. London: Routledge.

Chatterjee, K., Sherwin, H., Jain, J., Christensen, J., Marsh, S. (2013). A conceptual model to explain turning points in travel behaviour: application to bicycle use. Transportation Research Record 2322, 82-90.

Chatterjee, K., Scheiner, J. (2015). Understanding changing travel behaviour over the life course: contributions from biographical research. Presented at the 14th International Conference on Travel Behaviour Research, Windsor, UK, 19-23 July 2015.

Chatterjee, K., Goodwin, P., Schwanen, T., Clark, B., Jain, J., Melia, S., Middleton, J., Plyushteva, A., Ricci, M., Santos, G., Stokes, G. (2018). Young people's travel what's changed and why? review and analysis. Report to Department for Transport. UWE Bristol, UK.

Clarke, M., Dix, M., Goodwin, P. (1982). Some issues of dynamics in forecasting travel behaviour - a discussion paper. Transportation 11, 153-172.

Delbosc, A., McDonald, N., Stokes, G., Lucas, K., Circella, G., Lee, Y. (2019). Millennials in cities: comparing travel behaviour trends across six case study regions. Cities 90, 1-14.

De Vos, J., Ettema, D., Witlox, F. (2018). Changing travel behaviour and attitudes following a residential relocation. Journal of Transport Geography 73, 131-147.

Elder Jr., G. H., Johnson, M. K., Crosnoe, R. (2006). The emergence and development of life course theory. In Mortimer, J., Shanahan, M. J. (eds.). Handbook of the life course. Berlin: Springer, pp. 3-19.

Enoch, M. (2012). Sustainable transport, mobility management and travel plans. Farnham: Ashgate Publishing.

Finch, J., Mason, J. (1993). Negotiating family responsibilities. London: Routledge.

Frändberg, L. (2008). Paths in transnational time-space: representing mobility biographies of young Swedes. Geografiska Annaler B 90(1), S. 17-28.

Giele, J. Z., Elder Jr., G. H. (eds.) (1998). Methods of life course research: qualitative and quantitative approaches. Thousand Oaks, CA: Sage Publications.

Goetz, A., Vowles, T., Tierney, S. (2009). Bridging the qualitative-quantitative divide in transport geography. Professional Geographer 61(3), 323-335.

Goulias, K. G., Kitamura, R. (1997). A dynamic microsimulation model system for regional travel demand forecasting. In Golob, T. F., Kitamura, R., Long, L. (eds.). Panels for transportation planning: methods and applications. New York: Wiley, pp. 321-348.

Goulias, K., Pendyala, R. (2014). Choice context. In Hess, S., Daly, A. (eds.). Handbook of choice modelling. Cheltenham, UK and Northampton, MA, USA: Edward Elgar Publishing, pp. 101-130.

Hägerstrand, T. (1970). What about people in regional science? Papers in Regional Science 24, 7-21.

Hanson, S. (2010). Gender and mobility: new approaches for informing sustainability. Gender, Place and Culture 17(1), 5-23.

Hanson, S., Hanson, P. (1981). The travel-activity patterns of urban residents: dimensions and relationships to sociodemographic characteristics. Economic Geography 57(4), 332-347.

Ho, C., Mulley, C. (2015). Intra-household interactions in transport research: a review. Transport Reviews 35(1), 33-55. 
Hodgson, S., Namdeo, A., Araujo-Soares, V., Pless-Mulloli, T. (2012). Towards an interdisciplinary science of transport and health: a case study on school travel. Journal of Transport Geography 21, 70-79.

Holstein, J. A., Gubrium, J. F. (2000). Constructing the life course. Dix Hills, NY: General Hall.

Jones, P., Lucas, K. (2012). Social impacts and equity issues in transport: an introduction. Journal of Transport Geography 21, 1-3.

Kostyniuk, L., Kitamura, R. (1982). Life cycle and household time-space paths: empirical investigation. Transportation Research Record 879, 28-37.

Lanzendorf, M. (2003). Mobility biographies. A new perspective for understanding travel behaviour. Paper presented at the 10th International Conference on Travel Behaviour Research, Lucerne, 10-15 August 2003.

Lin, T., Wang, D. (2014). Social networks and joint/solo activity-travel behavior. Transportation Research Part A 68, 18-31.

Marsden, G., Docherty, I. (2013). Insights on disruptions as opportunities for transport policy change. Transportation Research Part A 51, 46-55.

Martensson, S. (1979). On the formation of biographies in space-time environments. Lund: Lund University Department of Geography.

Mattioli, G., Philips, I., Anable, J., Chatterton, T. (2019). Vulnerability to motor fuel price increases: socio-spatial patterns in England. Journal of Transport Geography $78,98-114$.

Miller, E. (2005). An integrated framework for modelling short and long run household decision making. In Timmermans, H. (ed.). Activity based analysis. Oxford: Elsevier, pp. 175-201.

Milne, E. M. (2012). A public health perspective on transport policy priorities. Journal of Transport Geography 21, 62-69.

Mínguez, A. M. (2016). Economic crisis and the new housing transitions of young people in Spain. International Journal of Housing Policy 16(2), 165-183.

Mortimer, J., Shanahan, M. J. (eds.) (2003). Handbook of the life course. New York: Springer.

Müggenburg, H., Busch-Geertsema, A., Lanzendorf, M. (2015). A review of achievements and challenges of the mobility biographies approach and a framework for further research. Journal of Transport Geography 46, 151-163.

Oakil, A. T. M. (2013). Temporal dependence in life trajectories and mobility decisions. $\mathrm{PhD}$ thesis. Utrecht.

Oakil, A. T. M., Ettema, D., Arentze, T., Timmermans, H. (2011). Longitudinal model of longer-term mobility decisions: framework and first empirical tests. Journal of Urban Planning and Development 137(3), 220-229.

Perlesz, A., Lindsay, J. (2003). Methodological triangulation in researching families: making sense of dissonant data. International Journal of Social Research Methodology 6(1), 25-40.

Plyushteva, A., Schwanen, T. (2018). Care-related journeys over the life course: thinking mobility biographies with gender, care and the household. Geoforum 97, 131-141.

Rasouli, S., Timmermans, H. (2017). Models of behavioral change and adaptation. In Zhang, J. (ed.). Life-oriented behavioral research for urban policy. Tokyo: Springer, pp. 451-477.

Rau, H., Manton, R. (2016). Life events and mobility milestones: Advances in mobility biography theory and research. Journal of Transport Geography 52, 51-60. 
Rau, H., Sattlegger, L. (2018). Shared journeys, linked lives: a relational-biographical approach to mobility practices. Mobilities 13(1), 45-63.

Rau, H., Popp, M., Namberger, P., Mögele, M. (2019). Short distance, big impact: the effects of intra-city workplace relocation on staff mobility practices. Journal of Transport Geography 79, 102483.

Roberts, B. (2002). Biographical research. Buckingham, PA: Open University Press.

Roby, H. (2010). Workplace travel plans: past, present and future. Journal of Transport Geography 18(1), 23-30.

Sackmann, R. (2007). Lebenslaufanalyse und biografieforschung. Wiesbaden: Springer.

Salomon, I., Ben-Akiva, M. (1983). The use of the life-style concept in travel demand models. Environment and Planning A 15 (5), 623-638.

Sattlegger, L., Rau, H. (2016). Carlessness in a car-centric world: a reconstructive approach to qualitative mobility biographies research. Journal of Transport Geography 53, 22-31.

Schäfer, M., Jaeger-Erben, M., Bamberg, S. (2012). Life events as windows of opportunity for changing towards sustainable consumption patterns? Journal of Consumer Policy 35(1), 65-84.

Scheiner, J. (2005). Daily mobility in Berlin: on 'inner unity' and the explanation of travel behaviour. European Journal of Transport and Infrastructure Research 5(3), $159-186$.

Scheiner, J. (2007). Mobility biographies: elements of a biographical theory of travel demand. Erdkunde 61(2), 161-173.

Scheiner, J. (2018). Why is there change in travel behaviour? In search of a theoretical framework for mobility biographies. Erdkunde 72(1), 41-62.

Schwanen, T. (2011). Car use and gender: the case of dual-earner families in Utrecht, The Netherlands. In Lucas, K., Blumenberg, E., Weinberger, R. (eds.). Auto motives: understanding car use behaviours. Bingley, UK: Emerald Publishing, pp. 151-171.

Schwartz, B. (2004). The paradox of choice: why more is less. New York: Harper.

Sharmeen, F., Arentze, T., Timmermans, H. (2014). An analysis of the dynamics of activity and travel needs in response to social network evolution and life-cycle events: a structural equation model. Transportation Research Part A 59, 159-171.

Timmermans, H., Arentze, T. A. (2011). Transport models and urban planning practice: experiences with Albatross. Transport Reviews 31(2), 199-207.

Van der Waerden, P., Timmermans, H., Borgers, A. (2003). The influence of key events and critical incidents on transport mode choice switching behaviour: a descriptive analysis. Paper presented at the 10th International Conference on Travel Behaviour Research, Lucerne, 10-15 August 2003.

Vogl, S., Schmidt, E. M., Zartler, U. (2019). Triangulating perspectives: ontology and epistemology in the analysis of qualitative multiple perspective interviews. International Journal of Social Research Methodology 22(6), 611-624.

Worth, N., Hardill, I. (eds.) (2015). Researching the lifecourse: critical reflections from the social sciences. Bristol: Policy Press. 